\title{
Intrafetal laser therapy in a monochorionic diamniotic triplet pregnancy with two acardiac fetuses: a case report and literature review
}

\author{
Guiqiong Huang ${ }^{1,2}$, Hua Liao ${ }^{1,2}$, Qing Hu ${ }^{1,2}$, Xiaodong Wang ${ }^{1,2}$ and Haiyan $\mathrm{Yu}^{1,2^{*}}$ (D)
}

\begin{abstract}
Background: Monochorionic diamniotic triplet pregnancies are rare. Twin reversed arterial perfusion sequence in monochorionic triplet pregnancies is extremely rare, and it is associated with high perinatal morbidity and mortality rates in the "pump fetus."

Case presentation: We reported a case of monochorionic diamniotic triplet pregnancy with twin reversed arterial perfusion sequence, including two acardiac fetuses sharing a single amniotic sac and a normal fetus in another amniotic sac. Due to rapid growth of the acardiac fetuses, intrafetal laser therapy was performed in both of them under ultrasound guidance at 15 weeks +5 days. Subsequently, regular and careful antenatal care including fetal ultrasonography and doppler and fetal echocardiography was conducted. At 37 weeks +4 days, a healthy female baby weighing $2510 \mathrm{~g}$ was delivered. The baby was followed up and now at 11 months old is in good health.

Conclusions: Twin reversed arterial perfusion sequence in monochorionic triplet pregnancy should be diagnosed early by ultrasound imaging during pregnancy. Individualized management should be based on clinical conditions to improve the perinatal outcome of the pump twin. Intrafetal laser therapy could be an alternative procedure when intrauterine intervention is required.
\end{abstract}

Keywords: Monochorionic diamniotic triplets, Twin reversed arterial perfusion sequence, Intrafetal laser therapy

\section{Background}

The incidence of triplet pregnancies has increased significantly in recent decades due to the use of assisted reproductive technology and the trend of delayed childbearing, with the most common type being trichorionic triamniotic pregnancy [1, 2]. Monochorionic triplet pregnancies occur at a rate of approximately 1 in 45,500 deliveries [3]. Monochorionic diamniotic (MCDA) triplet

\footnotetext{
* Correspondence: fanjy422@163.com

'Department of Obstetrics and Gynecology, West China Second University Hospital, Sichuan University, No. 20, 3rd section, South Renmin Road, Sichuan 610041 Chengdu, China

${ }^{2}$ Key Laboratory of Birth Defects and Related Diseases of Women and Children (Sichuan University), Ministry of Education, Chengdu, China
}

pregnancies are exceedingly rare compared with other types of triplet pregnancies. There have been only a few published articles relevant to MCDA triplet pregnancies so far, and the majority of them are case reports [4-15]. Triplet pregnancies are associated with higher perinatal morbidity and mortality as well as life-threatening maternal complications [16], especially in MCDA triplet pregnancies due to their special chorionic and amniotic properties.

Twin reversed arterial perfusion (TRAP) sequence is a rare and specific complication of monochorionic multiple pregnancies. The incidence of TRAP in monochorionic triplet pregnancies is approximately 1 in 4.5 million

(c) The Author(s). 2021 Open Access This article is licensed under a Creative Commons Attribution 4.0 International License, which permits use, sharing, adaptation, distribution and reproduction in any medium or format, as long as you give appropriate credit to the original author(s) and the source, provide a link to the Creative Commons licence, and indicate if changes were made. The images or other third party material in this article are included in the article's Creative Commons licence, unless indicated otherwise in a credit line to the material. If material is not included in the article's Creative Commons licence and your intended use is not permitted by statutory regulation or exceeds the permitted use, you will need to obtain permission directly from the copyright holder. To view a copy of this licence, visit http://creativecommons.org/licenses/by/4.0/. The Creative Commons Public Domain Dedication waiver (http://creativecommons.org/publicdomain/zero/1.0/) applies to the data made available in this article, unless otherwise stated in a credit line to the data. 
pregnancies [17]. Here, we reported a successful application of intrafetal laser therapy in an extremely rare case of MCDA triplet pregnancy with two acardiac fetuses and successful delivery of a healthy newborn at term at the West China Second University Hospital, a tertiary referral center in western China. The treatment procedure followed ethical principles; all data were collected from chart reviews, and an approval was obtained from the Institutional Review Board. Additionally, we conducted a literature review about TRAP sequence in monochorionic triplet pregnancies.

\section{Case presentation}

A 31-year-old woman, gravida 2 para 0, spontaneously conceived. Ultrasound examination at 12 weeks' gestation confirmed monochorionic diamniotic triplets including two acardiac fetuses (Fetus 2 and Fetus 3) sharing a single amniotic sac and one normal fetus ("pump fetus" or Fetus 1) in another amniotic sac. The patient's serology was negative for human immunodeficiency virus (HIV), venereal disease research laboratory (VDRL), and hepatitis B surface antigen (HBsAg), and she had no diabetes mellitus. The pregnant woman and her partner reported no history of medication, substance abuse, and family history of congenital anomalies. They were extensively counseled by the multidisciplinary team and the woman was followed up with serial fetal ultrasonography. Fetus 2 and Fetus 3 in one amniotic sac were malformed with dysplasia of the spine and lower limbs, and complete absence of the head, heart, and upper limbs.

Due to rapid growth of the acardiac fetuses, after repeated extensive counseling about the predicted poor prognosis of the pump fetus (Fetus 1) during expectant management, intrafetal laser therapy was performed under ultrasound guidance at 15 weeks +5 days. The18gauge needle (Hakko Co., Ltd., Japan) was introduced into one of the acardiac fetuses. A $400-\mu \mathrm{m}$ laser fiber was then passed through the needle and placed close to the pelvic vessels. Intrafetal laser therapy was performed using a NdYAG-laser source (Dornier MedTech, Wessling, Germany) in 5-s bursts at $10 \mathrm{~W}$ initial power, which was then doubled in steps to a maximum level of $20 \mathrm{~W}$, thereby resulting in cessation of blood flow in that acardiac fetus. After that, the18-gauge needle was introduced into the other acardiac fetus, and the same procedure was done. Images of increasing magnification showing the acardiac fetuses (F2 and F3) and their reversed blood flow before intrafetal laser therapy are shown in Fig. 1a. Images of the pump fetus and both


Fig. 1 a. Images of increasing magnification show the acardiac fetuses (F2 and F3) and their reversed blood flow before intrafetal laser therapy. b. Images of pump fetus and both acardiac fetuses after intrafetal laser therapy 
acardiac fetuses after intrafetal laser therapy are shown in Fig. 1b. The woman was followed up closely with fetal ultrasonography and doppler and fetal echocardiography.

The couple refused the chromosome examination in both acardiac fetuses, and amniocentesis was performed in the pump fetus. The result of chromosome microarray analysis in the pump fetus was normal.

At 37 weeks +4 days, a healthy female baby weighing $2510 \mathrm{~g}$ was delivered with Apgar scores of 10 and 10 at the first and fifth minute, respectively, whereas two papyraceous acardiac fetuses weighed 14 and $8 \mathrm{~g}$. Images of the monochorionic-diamniotic placenta and the papyraceous acardiac fetuses are shown in Fig. 2. The pathological results revealed monochorionic-diamniotic triplet pregnancy with two acardiac fetuses. The baby is now 11 months old and she is in good health.

\section{Discussion and conclusions}

TRAP sequence is characterized by the presence of an "acardiac twin" (with an absent or nonfunctioning heart) and a "pump twin" that provides perfusion that occurs exclusively in monochorionic multiple pregnancies. It is even more unusual in a triplet pregnancy. It is widely believed that the TRAP sequence is a result of abnormal vascular anastomoses between fetuses.

We used a list of keywords including "twin reversed arterial perfusion sequence," "TRAP sequence," "acardiac fetus," "acardiac twin," "triplets," "triplet pregnancy," and "multiple pregnancy" to perform an extensive search of literature in English and Chinese about the perinatal management and outcomes of monochorionic triplet pregnancies with TRAP sequence. The pump-acardiac complex in monochorionic triplets may present as one of the following three types: one acardiac with two pump fetuses; two acardiac fetuses with one pump fetus; one acardiac, one pump, and one unaffected fetus [17].

Our literature review revealed 17 published articles about monochorionic triplets with one acardiac fetus [17-33]. The management and perinatal outcomes of the acardiac fetus in monochorionic diamniotic triplet pregnancy and monochorionic triamniotic triplet pregnancy are shown in Table 1.

To the best of our knowledge, there have been only three published articles in English and Chinese related to two acardiac fetuses with one pump fetus in a triplet gestation [4-6]. Sanjaghsaz et al. [5] first described the case of a pregnant woman who delivered a live female baby and conjoined acardiac acephalic twins by cesarean section at 35 weeks' gestation. Ventura et al. [6] reported one case with two acardiac fetuses in monochorionic triamniotic triplet pregnancy. Spontaneous labor happened at $23+5$ weeks, and there was no fetal heart activity in the pump twin. Furthermore, May et al. [4] reported a case of TRAP sequence in a MCDA triplet pregnancy with two conjoined acardiac fetuses. A live healthy male infant weighing $1275 \mathrm{~g}$ and two conjoined acardiac fetuses were delivered at $27+6$ weeks. Detailed information of these cases is shown in Table 2.

With regard to the intrauterine intervention in multiple pregnancies with TRAP sequence, more studies have been conducted in twin than in triple pregnancies. The most widely used techniques in the management of TRAP pregnancies include ultrasound-guided ablation of intrafetal vessels by laser or radiofrequency (RFA) and bipolar cord coagulation because they are less invasive than endoscopic procedures [18]. Based on the literature [34], neonatal survival rate is comparable between RFA and intrafetal laser techniques ( 85 vs. $82 \%, P=0.63$ ), but the incidence of premature rupture of membranes before
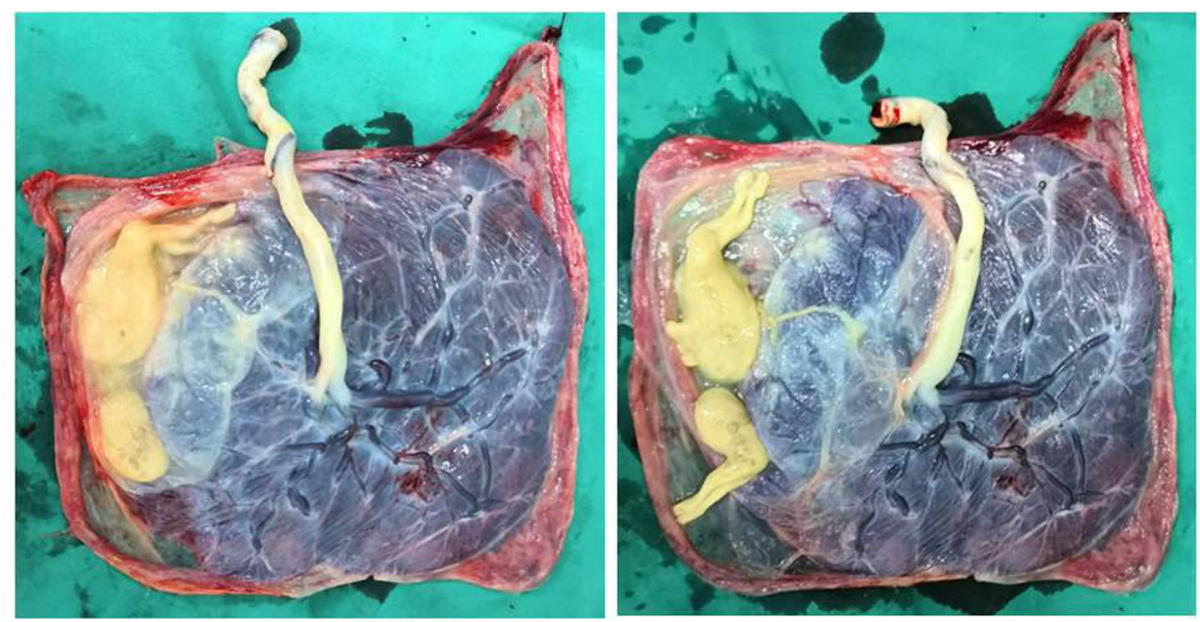

Fig. 2 Images of the monochorionic-diamniotic placenta and the papyraceous acardiac fetuses 


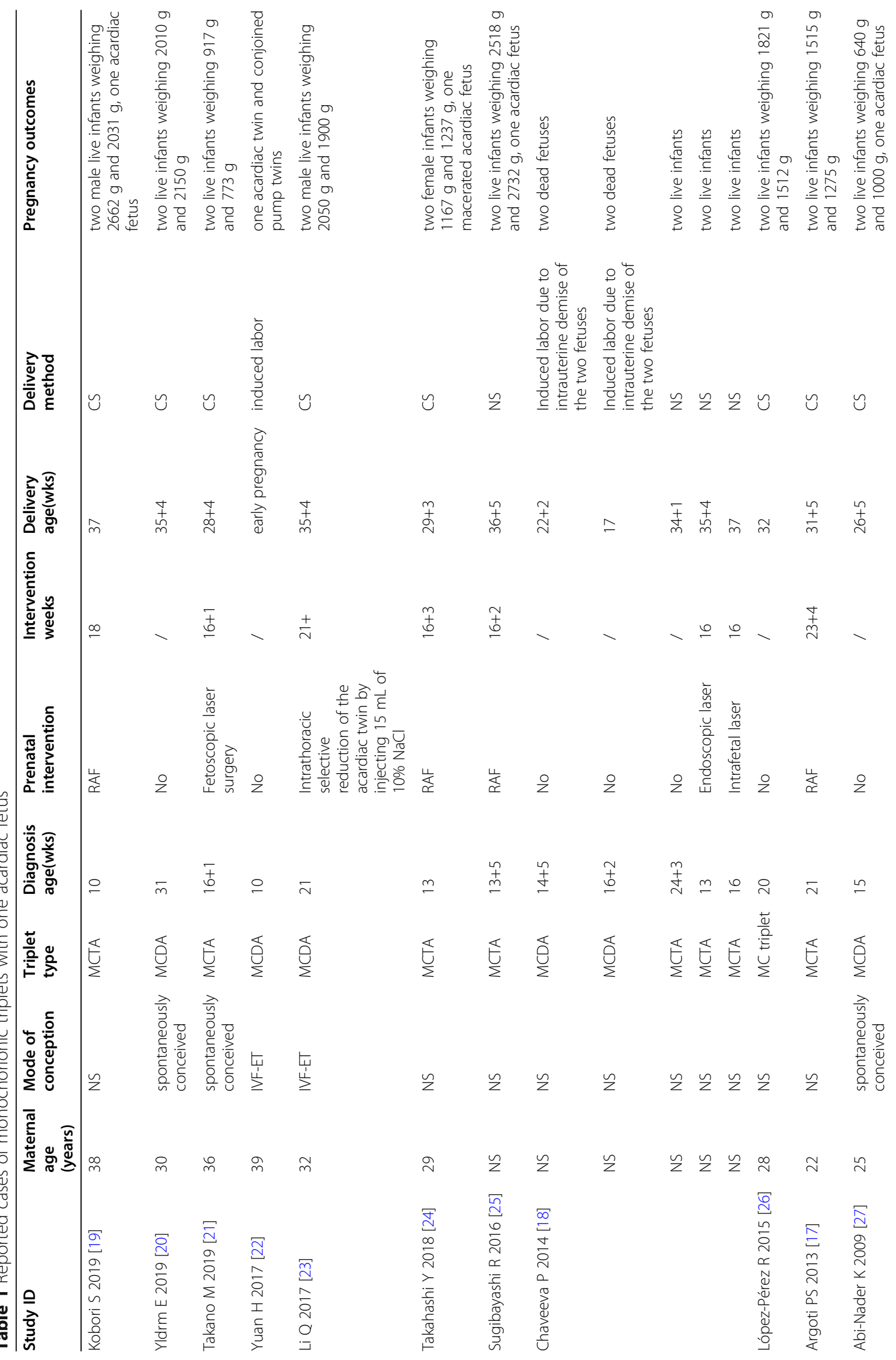




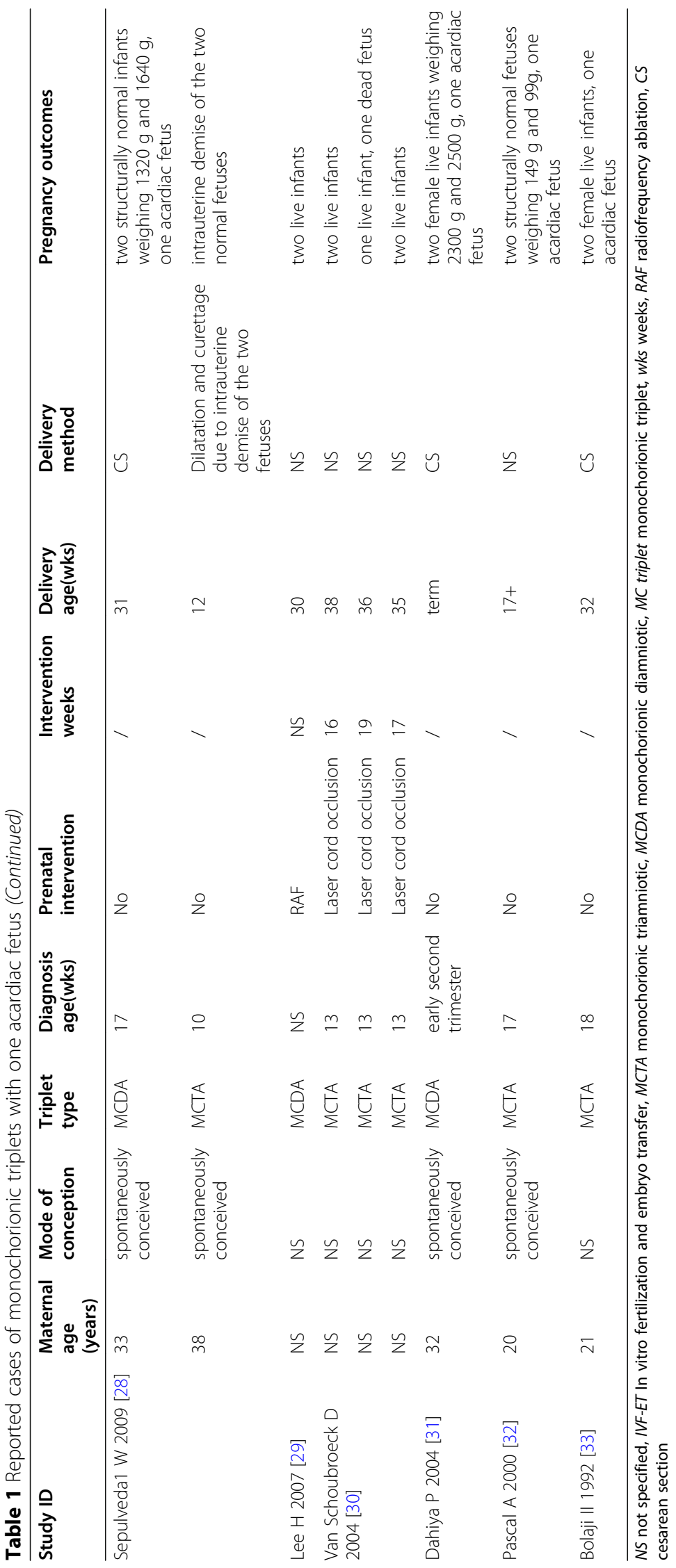


Table 2 The characteristics of triplets with two acardiac fetuses

\begin{tabular}{|c|c|c|c|c|c|c|c|c|}
\hline Study ID & $\begin{array}{l}\text { Maternal } \\
\text { age(years) }\end{array}$ & $\begin{array}{l}\text { Spontaneously } \\
\text { conceived }\end{array}$ & $\begin{array}{l}\text { Triplet } \\
\text { type }\end{array}$ & $\begin{array}{l}\text { Diagnosis } \\
\text { age(wks) }\end{array}$ & $\begin{array}{l}\text { Prenatal } \\
\text { intervention }\end{array}$ & $\begin{array}{l}\text { Delivery } \\
\text { age(wks) }\end{array}$ & $\begin{array}{l}\text { Delivery } \\
\text { method }\end{array}$ & Pregnancy outcomes \\
\hline $\begin{array}{l}\text { Sanjaghsaz } \\
1998 \text { [5] }\end{array}$ & 24 & NS & NS & At delivery & No & $35+1$ & CS & $\begin{array}{l}\text { A live infant weighing } 2646 \mathrm{~g} \\
\text { and conjoined acardiac acephalic } \\
\text { twins weighing } 1350 \mathrm{~g}\end{array}$ \\
\hline $\begin{array}{l}\text { Ventura } \\
2011[6]\end{array}$ & 30 & $\begin{array}{l}\text { spontaneously } \\
\text { conceived }\end{array}$ & MCTA & 21 & No & $23+5$ & VD & $\begin{array}{l}\text { Spontaneous labor and no fetal } \\
\text { heart activity in the pump twin, } \\
\text { pump twin weighing } 720 \mathrm{~g}, \\
\text { acardiac twins weighing } 862 \mathrm{~g}\end{array}$ \\
\hline $\begin{array}{l}\text { May } \\
2016[4]\end{array}$ & 30 & NS & MCDA & $26+1$ & No & $27+6$ & CS & $\begin{array}{l}\text { A live infant weighing } 1275 \mathrm{~g} \text { and } \\
\text { conjoined acardiac twins weighing } \\
940 \mathrm{~g}\end{array}$ \\
\hline Our case & 31 & $\begin{array}{l}\text { spontaneously } \\
\text { conceived }\end{array}$ & MCDA & 12 & $\begin{array}{l}\text { Intrafetal laser } \\
\text { therapy }\end{array}$ & $37+4$ & CS & $\begin{array}{l}\text { A healthy infant weighing } 2510 \mathrm{~g} \\
\text { and two papyraceous acardiac } \\
\text { fetuses weighing } 14 \text { and } 8 \mathrm{~g}\end{array}$ \\
\hline
\end{tabular}

NS not specified, MCTA monochorionic triamniotic, MCDA monochorionic diamniotic, wks weeks, VD vaginal delivery, CS cesarean section

32 weeks' gestation is significantly higher with RFA (22 vs. $7 \%, P=0.045$ ).

With the widespread development of color doppler ultrasound, TRAP sequence can be diagnosed at 11-13 weeks of gestation. An early diagnosis allows accurate determination of chorionicity and also prompts for closer surveillance of the pregnancy, with earlier opportunity for intrauterine intervention to improve the survival rate of the pump fetus. It has been shown that adverse pregnancy outcomes are significantly less frequent when intrafetal laser treatment is undertaken before 16 weeks (3/16, 19\%) compared with at or after 16 weeks ( $19 \%$ vs. $66 \% ; P=0.0025)$ [34]. Chaveeva et al. [18] found a significant inverse association between gestational age at treatment and gestational age at birth $(r=-0.297, P=0.007)$. The mean gestational age at birth was 38 and 34 weeks when treatment was carried out at 13 and 27 weeks, respectively. Intrafetal laser therapy was suggested at 12-14 weeks rather than delaying intervention until 16-18 weeks. Paganie et al. [34] suggested that it might be advisable to restrict the administration of intrafetal laser treatment to a therapeutic window between 13 and 16 weeks of gestation. However, there is no consensus on management of the TRAP sequence.

Here we reported the application of intrafetal laser therapy in the MCDA triplet pregnancy complicated by two acardiac fetuses. We chose intrafetal laser as the best option at 15 weeks +5 days to cease blood flow in both acardiac fetuses. After the procedure, the woman was stable throughout the pregnancy without complications. A full term newborn in good condition was finally delivered.

In conclusion, due to the rarity of triplet pregnancies with TRAP sequence, the experience with treatment is limited. Obstetricians and ultrasound specialists must be aware of the rare complication and focus on early ultrasound diagnosis. Individualized management should be based on fetal clinical conditions to improve the perinatal outcomes of the pump twin. Intrafetal laser therapy could be an alternative procedure when intrauterine intervention is required.

\section{Abbreviations \\ TRAP: Twin reversed arterial perfusion; MCDA: Monochorionic diamniotic; RFA: Radiofrequency ablation}

\section{Acknowledgements}

We are grateful to the doctors and staff who have been involved in this work. All persons that contributed to this study are listed as authors and meet the criteria for authorship.

\section{Authors' contributions}

$\mathrm{GQH}$ carried out the retrospective review of the case, participated in the design, writing, and organization of the manuscript. HYY conceived and designed the whole study, supervised the work, and revised the manuscript. XDW participated in the design of the study. $\mathrm{HL}$ and $\mathrm{QH}$ participated in the analysis of cases and literature review. All authors read and approved the final manuscript.

\section{Funding}

This study was supported by the Academic and Technical Leader's Foundation of Sichuan Province (No.2017-919-25). With the support of this fund, we were able to design the study and complete the data collection and analysis.

\section{Availability of data and materials}

The datasets used and/or analyzed during the current study are available from the corresponding author on reasonable request.

\section{Declarations}

Ethics approval and consent to participate Not applicable.

\section{Consent for publication}

Written informed consent for publication of this case report and any accompanying images was obtained from the couple. A copy of the written consent is available for review by the editor of this journal. 
Received: 7 November 2020 Accepted: 15 March 2021

Published online: 23 March 2021

\section{References}

1. Committee on Practice Bulletins-Obstetrics. Practice bulletin no. 169: multifetal gestations: twin, triplet, and higher-order multifetal pregnancies. Obstet Gynecol. 2016:128(4):e131-46.

2. Geipel A, Berg C, Katalinic A, et al. Prenatal diagnosis and obstetric outcomes in triplet pregnancies in relation to chorionicity. BJOG: An International Journal of Obstetrics Gynaecology. 2005;112(5):554-8.

3. Imaizumi Y. A Comparative Study of Zygotic Twinning and Triplet Rates in Eight Countries, 1972-1999. J Biosoc Sci. 2003;35(2):287-302.

4. May JS, Lanni S, Jakowski JD. A case of twin reversed arterial perfusion (TRAP) sequence in a monochorionic diamniotic triplet pregnancy with two acardiac fetuses. Int J Diag Imagi. 2016;3(2):59-64.

5. Sanjaghsaz H, Bayram MO, Qureshi F. Twin reversed arterial perfusion sequence in conjoined, acardiac, acephalic twins associated with a normal triplet. J Reprod Med. 1998:43:1046-50.

6. Ventura W, Nazario C, Ventura J. Triplet pregnancy complicated by two acardiac fetuses. Ultrasound Obstet Gynecol. 2011;38(3):362-3.

7. Xu T, Wang $X, Y u H$, Liu X. Perinatal outcomes of monochorionic diamniotic triplet pregnancies: a case series. BMC Pregnancy Childbirth. 2019;19(1):496.

8. Suizu A, Sato Y, Maruyama S, et al. Successful management of monochorionic diamniotic triplet pregnancy. J Obstet Gynaecol. 2016; 36(6):758-9.

9. Yıldırım E. Spontaneous triplet pregnancy and trap sequence, case report. BMC Pregnancy Childbirth. 2019;19(1):328.

10. Anglim B, Levins K, Bussmann N, Imcha M. Severe hyponatraemia associated with pre-eclampsia. BMJ Case Rep. 2016;2016N

11. Yonetani N, Ishii K, Mabuchi A, Sasahara J, Hayashi S, Mitsuda N. Prenatally diagnosed monochorionic diamniotic triplet pregnancy. J Obstet Gynaecol Res. 2015;41(8):1266-8

12. Youssef A, Milano V, Pilu G, Pelusi G, Ghi T. Three-dimensional sonograph of a monochorionic diamniotic triplet pregnancy. J Clin Ultrasound. 2012:40(4):227-30.

13. Sepulveda W, Wong AE, Bustos JC, Flores X, Alcalde JL. Acardiac fetus complicating a triplet pregnancy: management and outcome. Prenat Diagn. 2009;29(8):794-9.

14. Yong PJ, Farquharson DF, Ubhi J. Monochorionic Diamniotic Triplet Pregnancy With Prenatal Diagnosis of Cord Entanglement. J Obstet Gynaecol Canada. 2010;32(3):274-7.

15. Sepulveda W, Munoz $H$, Alcalde $J$. Conjoined twins in a triplet pregnancy: early prenatal diagnosis with three-dimensional ultrasound and review of the literature. Ultrasound Obstet Gynecol. 2003;22(2):199-204.

16. Luke B, Brown MB. Maternal morbidity and infant death in twin vs triplet and quadruplet pregnancies. Am J Obstet Gynecol. 2008;198(4):401.e401 401.e410.

17. Argoti PS, Bebbington MW, Johnson A, Moise KJ. Indirect pump: unique presentation of a monochorionic-triamniotic triplet gestation complicated by TRAP sequence and successfully managed with radiofrequency ablation of the acardiac fetus. Ultrasound Obstet Gynecol. 2013;42(1):115-7.

18. Chaveeva P, Poon LC, Sotiriadis A, Kosinski P, Nicolaides KH. Optimal Method and Timing of Intrauterine Intervention in Twin Reversed Arterial Perfusion Sequence: Case Study and Meta-Analysis. Fetal Diagn Ther. 2014 35(4):267-79.

19. Kobori S, Toshimitsu M, Nagaoka S, Murotsuki J. A Case of MonochorionicTriamniotic Triplet Pregnancy with TRAP Sequence Successfully Treated with Radiofrequency Ablation with a Parallel Circuit Consisting of Anastomosed Blood Vessels between the Direct Pump Fetus and the Indirect Pump Fetus. Case Rep Obstetr Gynecol.2019;2019:5319028.

20. Yldrm E. Spontaneous triplet pregnancy and trap sequence, case report. BMC Pregnancy Childbirth. 2019;19(1):328

21. Takano M, Nakata M, Rikitake T, Nagasaki S, Hayata E, Morita M. Successful use of fetoscopic laser surgery as treatment for a monochorionic-triamniotic triplet pregnancy complicated by twin-reversed arterial perfusion sequence and severe selective fetal growth restriction: A case report. J Obstet Gynaecol Res. 2019;45:1584-7.

22. Yuan H, Zhou Q, Li J, Shi Z. Triplet pregnancy from the transfer of two blastocysts demonstrating a twin reversed arterial perfusion sequence with a conjoined-twins pump fetus. Int J Gynecol Obstet. 2017;137(2):196-7.
23. Li Q, Wu XH, Zhang WS. A new method for selective reduction in TRAP sequence with a contraindication to fetoscopic surgery: A case report. Medicine. 2017;96(10):e6250.

24. Takahashi Y, Iwagaki S, Chiaki R, Asai K, Matsui M, Kawabata I. Ultrasonic identification of pump twin by dual-gate Doppler in a monochorionictriamniotic triplet twin reversed arterial perfusion sequence before preventative radiofrequency ablation: a case report. J Med Ultrason (2001) 2018;45(1):185-187.

25. Sugibayashi R, Ozawa K, Sumie M, Wada S, Ito $Y$, Sago H. Forty cases of twin reversed arterial perfusion sequence treated with radio frequency ablation using the multistep coagulation method: a single-center experience. Prenat Diagn. 2016;36(5):437-43

26. López-Pérez R, Lorente M, Martínez-Uriarte J, Rivero IM, García-lzquierdo O, Jódar MA. Twin-Reversed Arterial Perfusion Sequence in a Triple Monochorionic Pregnancy with Two Direct Pump Fetuses Results in Significant Cyclic Doppler Waveform. Fetal Diagn Ther. 2015;37(2):157-60.

27. Abi-Nader K, Whitten SM, Filippi E, et al. Dichorionic Triamniotic Triplet Pregnancy Complicated by Acardius Acormus. Fetal Diagn Ther. 2009; 26(1):45-9.

28. Sepulveda1 W, Wong AE, Bustos JC, Flores X, Alcalde JL. Acardiac fetus complicating a triplet pregnancy: management and outcome. Prenat Diagn. 2009:29(8):794-9.

29. Lee H, Wagner AJ, Sy E, Ball R, Feldstein VA, Goldstein RB. Efficacy of radiofrequency ablation for twin-reversed arterial perfusion sequence. Am J Obstet Gynecol. 2005;196(5):459.e1-e4.

30. Van Schoubroeck D, Lewi L, Ryan G, Carreras E, Jani J, Hiqueras T, et al. Fetoscopic surgery in triplet pregnancies: a multicenter case series. Am J Obstet Gynecol. 2004;191(5):1529-32.

31. Dahiya P, Agarwal U, Sangwan K, Sen J. Antenatal diagnosis of twinreversed arterial perfusion sequence (acardiac amorphous) in a triplet pregnancy: case report. Arch Gynecol Obstet. 2004;269(2):147-8.

32. Pascal A, Renaud G, Georgette M, René G, Dominique G, Christian Q. Acardiac fetus in a triplet pregnancy: ultrasound pitfalls: A case report. Eur J Obstet Gynecol Reprod Biol. 2000;89(1):75-80.

33. Bolaji II, Mortimer G, Meehan FP, England S, Greally M. Acardius in a Triplet Pregnancy: Cytogenetic and Morphological Profile. Acta Genet Med Gemellol (Roma). 1992:41(1):27-32.

34. Pagani G, D'Antonio F, Khalil A, Papageorghiou A, Bhide A, Thilaganathan B. Intrafetal laser treatment for twin reversed arterial perfusion sequence: cohort study and meta-analysis. Ultrasound Obstet Gynecol. 2013;42(1):6-14

\section{Publisher's Note}

Springer Nature remains neutral with regard to jurisdictional claims in published maps and institutional affiliations.

Ready to submit your research? Choose BMC and benefit from:

- fast, convenient online submission

- thorough peer review by experienced researchers in your field

- rapid publication on acceptance

- support for research data, including large and complex data types

- gold Open Access which fosters wider collaboration and increased citations

- maximum visibility for your research: over $100 \mathrm{M}$ website views per year

At BMC, research is always in progress.

Learn more biomedcentral.com/submissions 